\title{
The Relation Between Official WhatsApp-Distributed COVID-19 News Exposure and Psychological Symptoms: Cross-Sectional Survey Study
}

Jean C J Liu ${ }^{1}, \mathrm{PhD}$; Eddie M W Tong ${ }^{2}$, PhD

${ }^{1}$ Yale-NUS College, Singapore, Singapore
${ }^{2}$ Department of Psychology, National University of Singapore, Singapore, Singapore

Corresponding Author:

Jean C J Liu, PhD

Yale-NUS College

02-221

16 College Avenue West

Singapore, 138527

Singapore

Phone: 6566013694

Email: jeanliu@yale-nus.edu.sg

\section{Abstract}

Background: In a global pandemic, digital technology offers innovative methods to disseminate public health messages. As an example, the messenger app WhatsApp was adopted by both the World Health Organization and government agencies to provide updates on the coronavirus disease (COVID-19). During a time when rumors and excessive news threaten psychological well-being, these services allow for rapid transmission of information and may boost resilience.

Objective: In this study, we sought to accomplish the following: (1) assess well-being during the pandemic; (2) replicate prior findings linking exposure to COVID-19 news with psychological distress; and (3) examine whether subscription to an official WhatsApp channel can mitigate this risk.

Methods: Across 8 weeks of the COVID-19 outbreak (March 7 to April 21, 2020), we conducted a survey of 1145 adults in Singapore. As the primary outcome measure, participants completed the Depression, Anxiety, and Stress Scale (DASS-21). As predictor variables, participants also answered questions pertaining to the following: (1) their exposure to COVID-19 news; (2) their use of the Singapore government's WhatsApp channel; and (3) their demographics.

Results: Within the sample, $7.9 \%$ of participants had severe or extremely severe symptoms on at least one DASS-21 subscale. Depression scores were associated with increased time spent receiving COVID-19 updates, whereas use of the official WhatsApp channel emerged as a protective factor $(b=-0.07, t[863]=-2.04, P=.04)$. Similarly, increased anxiety scores were associated with increased exposure to both updates and rumors, but this risk was mitigated by trust in the government's WhatsApp messages $(b=-0.05, t[863]=-2.13, P=.03)$. Finally, although stress symptoms increased with the amount of time spent receiving updates, these symptoms were not significantly related to WhatsApp use.

Conclusions: Our findings suggest that messenger apps may be an effective medium for disseminating pandemic-related information, allowing official agencies to reach a broad sector of the population rapidly. In turn, this use may promote public well-being amid an "infodemic."

Trial Registration: ClinicalTrials.gov NCT04305574; https://clinicaltrials.gov/ct2/show/NCT04305574

(J Med Internet Res 2020;22(9):e22142) doi: 10.2196/22142

\section{KEYWORDS}

mental health; social media; pandemic; depression; anxiety; stress; COVID-19; app; risk factor; psychology 


\section{Introduction}

On March 11, 2020, the World Health Organization (WHO) declared that the outbreak of coronavirus disease (COVID-19) had become a global pandemic [1,2]. Within six months of the first reported case (in December 2019), more than 9 million people have been infected in over 200 countries and territories [3]. In response, an estimated 1 in 3 individuals worldwide have been placed under mandatory quarantines or movement restrictions as part of wide-ranging measures to control transmission [4].

Given the magnitude of the crisis, several studies have begun to document its impact on mental health [5]. For example, one study in China found that nearly all patients with COVID-19 (96\%) had symptoms of posttraumatic stress disorder [6]. Within the general population, several studies have also recorded elevated levels of depression, anxiety, stress, and other psychological symptoms [2,7-9]. These findings underscore the need to address mental health as part of the broader public health response [10].

Preliminary research suggests that psychological symptoms during the outbreak are most common among those with preexisting health conditions [2], contacts of confirmed cases [2], and migrant and health workers [8,11]. Age, gender, and educational level have also been implicated as risk factors [7,8,11]. Although these demographic and situational characteristics allow vulnerable individuals to be identified, a separate set of risk factors may prove modifiable - those pertaining to the receipt of COVID-19 news.

To date, resilience during the pandemic has been observed when individuals receive regular updates on COVID-19 [2] and when they perceive the information to be adequate [2]. However, spending excessive time reading updates is associated with poorer outcomes [11-13]. Related to information availability, individuals also fare more poorly when they lack confidence in the health care infrastructure, and when they worry about potential infections among family members [2]. To the extent that these constitute modifiable risk factors, mitigation may be achieved when official government and transgovernmental bodies disseminate accurate and timely information, engendering trust in the management of COVID-19. This is particularly crucial in an age of social media, where false information has spread so rapidly that the WHO termed this an "infodemic" (a portmanteau of information and pandemic) [14].

Given this landscape, several governments have capitalized on social media itself to engage the public $[15,16]$. Notably, a growing number of countries-including Australia, Singapore, and the United Kingdom-have used the platform WhatsApp to provide COVID-19 updates (eg, [17]), as has the WHO [18]. Since WhatsApp is the most widely used messaging platform worldwide, these channels allow governments to access large segments of the population [19]. Further, messages can be sent near-instantly, co-opting the very channel used to disseminate false information. Accordingly, platforms like WhatsApp may prove ideal for boosting psychological resilience during this global pandemic.
Despite the potential of messenger-based channels, it remains unclear how effective these are since few health crises have arisen since WhatsApp was introduced in 2009 [20]. To address this gap, we conducted a large-scale survey with the following aims: (1) assess population mental health during the outbreak; (2) replicate findings on how news exposure may predispose an individual to distress; and (3) assess whether receiving updates through official WhatsApp channels can mitigate risk.

Our study was conducted across two months in Singapore, a city state that reported its first case early in the outbreak (January 23, 2020). During the survey period, Singapore experienced a rapid increase in COVID-19 cases, from 138 cases on March 7 (or 24 per million population), to 9125 cases on April 21 (1600 per million population). Consequently, a nationwide lockdown was imposed during the survey period, on April 7. Central to our question, from the outset of the crisis the Singapore government also deployed a WhatsApp subscription service that provided twice-daily updates on the local situation (eg, number of new cases, new infection control measures). At the time of the survey, this had been adopted by approximately 1 in 10 residents [21], providing a natural experiment to evaluate its impact.

\section{Methods}

\section{Study Design and Population}

Across an 8-week span (March 7 to April 21, 2020), we recruited 1145 adults who were aged 21 years and older, and had lived in Singapore for at least 2 years. Participants responded to advertisements placed in Facebook and WhatsApp community groups (eg, groups for residential estates, universities, and workplaces), or to paid Facebook advertisements targeting Singapore-based users who were at least 21 years old. The study was approved by the Yale-NUS College Ethics Review Committee (2020-CERC-001) and was preregistered on ClinicalTrials.gov (NCT04305574). In accordance with the Declaration of Helsinki, all participants gave their consent online prior to completing the survey. Participants received no inconvenience fee for their involvement, and were referred to the Ministry of Health's COVID-19 website at the end of the study.

\section{Predictor Variables}

Following informed consent, participants completed a 10-minute survey hosted on the online platform Qualtrics [22]. The survey was written at a seventh grade reading level, and was pilot tested for clarity.

As predictors, participants were asked questions pertaining to the following: (1) their exposure to COVID-19 news; (2) their use of the government's WhatsApp channel; and (3) demographics.

\section{Exposure to COVID-19 News}

To monitor the amount of time spent receiving and discussing COVID-19 news [11], participants were asked to estimate how much time they spent daily getting updates about COVID-19 (eg, searching and reading news) and using social media to discuss or share information. To provide a context for these 
values, they were also asked whether they spent more, the same, or less time each day being updated with the news and using social media compared to preoutbreak. However, these questions were highly correlated with time estimates and were not included in the statistical analyses.

As the quality of information received has also been found to predict well-being [13], participants were additionally asked about their exposure to COVID-19 rumors. Specifically, participants were shown 5 common myths that have been propagated about COVID-19 ("drinking water frequently will help to prevent infection," "eating garlic can help to prevent infection," "the outbreak came about because of people eating bat soup," "the virus was created in a US lab to affect China's economy," and "the virus was created in a Chinese lab as a bioweapon") [23]. For each claim, participants indicated the following: (1) whether they had heard the claim before; (2) whether they had shared it on social media; and (3) whether they thought it was true [24]. An affirmative response was counted as " 1 ", and scores were summed across claims to create three subscale scores (corresponding to the hearing, sharing, and belief of claims).

\section{Use of an Official WhatsApp Channel}

As the primary predictors of interest, participants were asked 3 questions pertaining to their use of the government's WhatsApp channel. Shortly after the first local cases in Singapore (at the end of January 2020), the government began using a subscription-based WhatsApp channel to send out COVID-19 updates in the country's 4 primary languages (English, Mandarin, Malay, and Tamil). On average, these messages were sent twice a day. The content of these messages included the following: (1) providing an update on confirmed cases ("There are 4 new confirmed cases."); (2) debunking rumors (eg, "The Prime Minister is not addressing the nation tonight, nor is Singapore locking down."); (3) disseminating new knowledge (eg, "How does it spread?"); (4) describing infection control measures (eg, "All sports and recreation facilities will be closed."); (5) describing economic and social support (eg, "Tourism, transport, retail and F\&B sectors get additional support."); or (6) responding to ad hoc events on the ground (eg, "Stay calm; don't panic buy."). Messages were written in brief sentences or in point form, with key phrases emphasized in bold (eg, "Observe good personal hygiene, be socially responsible") and with the use of emoticons (eg, - ). When the study began, this service had 635,000 unique subscribers out of Singapore's resident population of nearly 6 million individuals (approximately 10\%) [21].

To capture WhatsApp usage, participants indicated the following: (1) whether they had used the government's WhatsApp channel to receive COVID-19 news (yes/no); (2) how likely they were to share or forward messages from the channel (using 4-point scales anchored with "will definitely not forward on" and "will definitely forward on"); and (3) how likely they were to trust a message from this source (using 4-point scales anchored with "do not trust at all" and "trust completely").
As a basis of comparison, participants also indicated their use of, willingness to share or forward messages from, and trust of 12 possible news sources. These ranged from traditional sources (eg, printed newspapers, radio) to social media (eg, Facebook, YouTube).

\section{Demographics}

As the final category of predictors, participants reported their gender, ethnicity, religion, country of birth, country of citizenship, marital status, education, house type (as a proxy of socioeconomic status), and household size. Based on the survey time stamp, we also recorded the total number of local cases reported to date, and whether the country was locked down at the time of survey completion.

\section{Outcome Measures}

\section{Depression, Anxiety, and Stress Scale}

As the key outcome measure, participants completed the 21-item Depression, Anxiety, and Stress Scale (DASS-21), a widely used assay of depression (eg, "I felt that I had nothing to look forward to"; Cronbach $\alpha=0.90$ ), anxiety (eg, "I felt I was close to panic"; Cronbach $\alpha=0.80$ ), and stress symptoms (eg, "I found it hard to wind down"; Cronbach $\alpha=0.89$ ) previously validated within this population [25]. During the COVID-19 outbreak, the DASS-21 has also been used to measure psychological symptoms in both community and patient populations $[2,26]$.

\section{Expectations and Behavioral Responses Toward the Outbreak}

As secondary outcome measures, participants reported their reactions to the COVID-19 outbreak. First, participants were asked about their perceptions regarding the following [27]: (1) how confident they were that the government could control the nationwide spread of COVID-19 (answered using 4-point scales anchored with "not confident at all" and "very confident"); (2) how likely it was that they or someone in their immediate household would be infected with COVID-19 (using 4-point scales anchored with "not at all likely" and "very likely"); and (3) how fearful they were about the COVID-19 situation in Singapore (using 4-point scales anchored with "not scared at all" and "very scared").

Finally, participants also indicated which of 19 possible measures they had undertaken because of the outbreak (eg, "washed my hands more frequently," "relied more on online shopping," "kept a distance from people suspected of recent contact with a COVID-19 case") [28,29].

\section{Statistical Analysis}

First, to describe participants' baseline characteristics, survey responses were summarized by total numbers (with percentages) and medians (with interquartile ranges). For the primary analyses, we then ran a series of linear regression models with DASS-21 subscale scores as outcome measures.

In the first model, we sought to replicate findings identifying the receipt of COVID-19 news as a risk factor for psychological symptoms. Correspondingly, this model included the following predictors: (1) two questions pertaining to the time spent processing COVID-19 news (the number of hours spent getting 
updates each day, and the number of hours spent using social media to discuss or share COVID-19 information), and (2) three questions on COVID-19 rumors (the number of rumors heard, shared, and believed).

For the second model, we explored whether the use of an official WhatsApp channel could be protective, having factored in individual differences in the receipt of COVID-19 news. Here, we repeated the first model with three additional predictors: use of the government's WhatsApp channel, trust in its messages, and likelihood of sharing its messages (see Multimedia Appendix 1 for Spearman correlations for these predictors).

Finally, we ran two further models to assess the robustness of our findings, controlling for the outbreak situation (Model 3: implementation of a lockdown, and the number of local cases at the point of survey completion) and demographic variables (Model 4: age, gender, ethnicity, religion, marital status, education, house type, household size, and country of birth).

To achieve linearity, the following variables were log-transformed for regression analyses: DASS-21 subscale scores, time spent getting COVID-19 updates, time spent using social media, and the number of local COVID-19 cases. For each model, the type 1 decision-wise error rate was controlled at $=0.05$, and power calculations showed statistical power at the 0.90 level to detect small effect sizes $\left(f^{2}=0.01\right)$. Statistical analyses were conducted using SPSS (Version 25; IBM Corp) and R (Version 3.4.0; R Foundation for Statistical Computing).

\section{Results}

\section{Response Rate}

Of 1390 individuals who clicked the survey link, 1145 (82.4\%) provided informed consent and participated in the study. As shown in Table 1, the final sample was comparable to the resident population for the following variables: the proportion of Singapore citizens, marital status, and household size $(\leq 10 \%$ difference). However, the pool of respondents had a greater representation of females (62.4\% versus $51.1 \%$ ), university graduates $(67.2 \%$ versus $32.4 \%)$, persons aged $21-34$ (40.8\% versus $25.86 \%$ ), and persons of no religion $(26.6 \%$ versus $18.5 \%$ ) or Christian belief (34.1\% versus $18.8 \%$ ). Conversely, there was a reduced representation of participants who lived in 1- to 3 -room public housing flats (7.3\% versus $23.7 \%$ ). Survey respondents were also more likely to be of Chinese ethnicity than persons in the general population $(83.4 \%$ versus $74.3 \%)$. 
Table 1. Baseline characteristics of survey respondents $(\mathrm{N}=1145)$.

\begin{tabular}{|c|c|}
\hline Characteristic & Participants, n (\%) \\
\hline \multicolumn{2}{|l|}{ Age group (years) } \\
\hline $21-34$ & $467(40.8)$ \\
\hline $35-49$ & $394(34.4)$ \\
\hline $50-64$ & $220(19.2)$ \\
\hline$\geq 65$ & $64(5.6)$ \\
\hline Did not answer & $0(0)$ \\
\hline \multicolumn{2}{|l|}{ Gender } \\
\hline Female & $715(62.4)$ \\
\hline Male & $382(33.4)$ \\
\hline Did not answer & $48(4.2)$ \\
\hline \multicolumn{2}{|l|}{ Ethnicity } \\
\hline Chinese & $955(83.4)$ \\
\hline Indian & $53(4.6)$ \\
\hline Malay & $30(2.6)$ \\
\hline Filipino & $18(1.6)$ \\
\hline Caucasian & $14(1.2)$ \\
\hline Other & $27(2.4)$ \\
\hline Did not answer & $48(4.2)$ \\
\hline \multicolumn{2}{|l|}{ Religion } \\
\hline Christianity (Protestant) & $390(34.1)$ \\
\hline No religion & $305(26.6)$ \\
\hline Buddhism & $168(14.7)$ \\
\hline Roman Catholicism & $110(9.6)$ \\
\hline Taoism/Chinese traditional beliefs & $45(3.9)$ \\
\hline Islam & $37(3.2)$ \\
\hline Hinduism & $32(2.8)$ \\
\hline Other & $9(0.8)$ \\
\hline Did not answer & $49(4.3)$ \\
\hline \multicolumn{2}{|l|}{ Marital status } \\
\hline Married & $613(53.5)$ \\
\hline Single & $319(27.9)$ \\
\hline Dating & $114(10.0)$ \\
\hline Widowed, separated, or divorced & $31(2.7)$ \\
\hline Did not answer & $68(5.9)$ \\
\hline \multicolumn{2}{|l|}{ Educational level } \\
\hline 1: Primary school & $3(0.3)$ \\
\hline 2: Secondary school & $62(5.4)$ \\
\hline 3: Junior college & $93(8.1)$ \\
\hline 4: Vocational training & $16(1.4)$ \\
\hline 5: Polytechnic or diploma & $129(11.3)$ \\
\hline 6: University (undergraduate) & $541(47.2)$ \\
\hline 7: University (postgraduate) & $229(20.0)$ \\
\hline
\end{tabular}




\begin{tabular}{|c|c|}
\hline Characteristic & Participants, n (\%) \\
\hline Other & $4(0.3)$ \\
\hline Did not answer & $68(5.9)$ \\
\hline \multicolumn{2}{|l|}{ House type } \\
\hline 1: Public housing flat: $1-2$ rooms & $9(0.8)$ \\
\hline 2: Public housing flat: 3 rooms & $74(6.5)$ \\
\hline 3: Public housing flat: 4 rooms & $263(23.0)$ \\
\hline 4: Public housing flat: 5 rooms or executive flats & $300(26.2)$ \\
\hline 5: Condominium or private apartments & $291(25.4)$ \\
\hline 6: Landed property & $127(11.1)$ \\
\hline Other & $13(1.1)$ \\
\hline Did not answer & $68(5.9)$ \\
\hline \multicolumn{2}{|l|}{ Household size } \\
\hline 1 & $52(4.5)$ \\
\hline 2 & $143(12.5)$ \\
\hline 3 & $242(21.1)$ \\
\hline 4 & $327(28.6)$ \\
\hline$\geq 5$ & $313(27.3)$ \\
\hline Did not answer & $68(5.9)$ \\
\hline \multicolumn{2}{|l|}{ Citizenship } \\
\hline Singapore & $964(84.2)$ \\
\hline Other & $133(11.6)$ \\
\hline Did not answer & $48(4.2)$ \\
\hline \multicolumn{2}{|l|}{ Country of birth } \\
\hline Singapore & $876(76.5)$ \\
\hline Other & $221(19.3)$ \\
\hline Did not answer & $48(4.2)$ \\
\hline \multicolumn{2}{|l|}{ Years in Singapore } \\
\hline$\leq 20$ & $186(16.2)$ \\
\hline $21-34$ & $420(36.7)$ \\
\hline $35-49$ & $304(26.6)$ \\
\hline $50-64$ & $190(16.6)$ \\
\hline$\geq 65$ & $45(3.9)$ \\
\hline Did not answer & $0(0)$ \\
\hline
\end{tabular}

\section{Characterizing the Sample: DASS-21 Symptoms and COVID-19 Responses}

We first sought to characterize our sample participants in terms of their responses to the outbreak. As shown in Figure 1, the average participant was "not very scared" about the COVID-19 situation (median rating of $2, \mathrm{IQR} 2-3$ ), deemed it "not too likely" that they or a household member would be infected (median rating of 2, IQR 2-3), and was "somewhat confident" that the government could control the nationwide spread (median rating of 2, IQR 1-2). Most participants $(96.9 \%, 95 \%$ CI 95.7\%-98.0\%) had also voluntarily changed their behavior as a function of the outbreak, adopting measures such as handwashing or avoiding crowds (Figure 1). 
Figure 1. Responses to the COVID-19 outbreak. (A) Participants reported how fearful they were about the COVID-19 situation (top: left-most panel), the likelihood that they or a household member would test positive for COVID-19 (middle panel), and their confidence in the government's ability to control the outbreak (right-most panel). (B) Additionally, participants also reported the behavioral measures they adopted in response to the outbreak. Vertical lines represent the $95 \%$ confidence intervals.

(A) Fear about the CoVID-19 situation

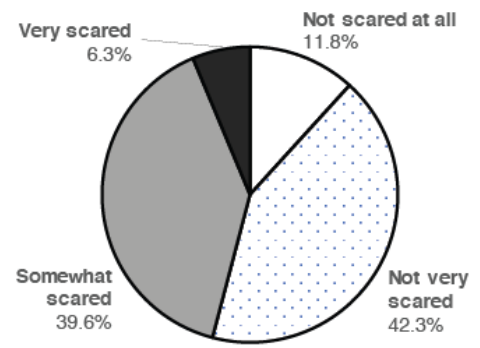

Perceived likelihood of self or household member getting COVID-19

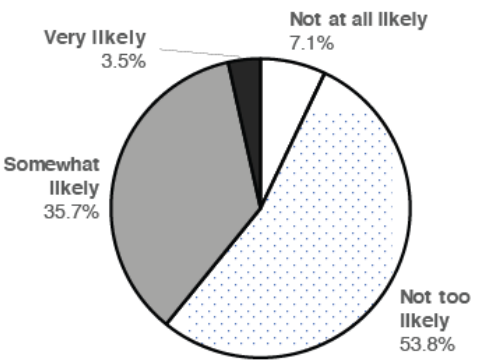

Confidence in government's ability to control COVID-19

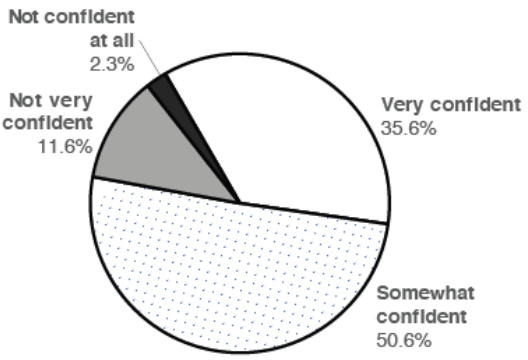

(B) Responding to the CoVID-19 outbreak: Changes in behavior (\% respondents reporting this change)

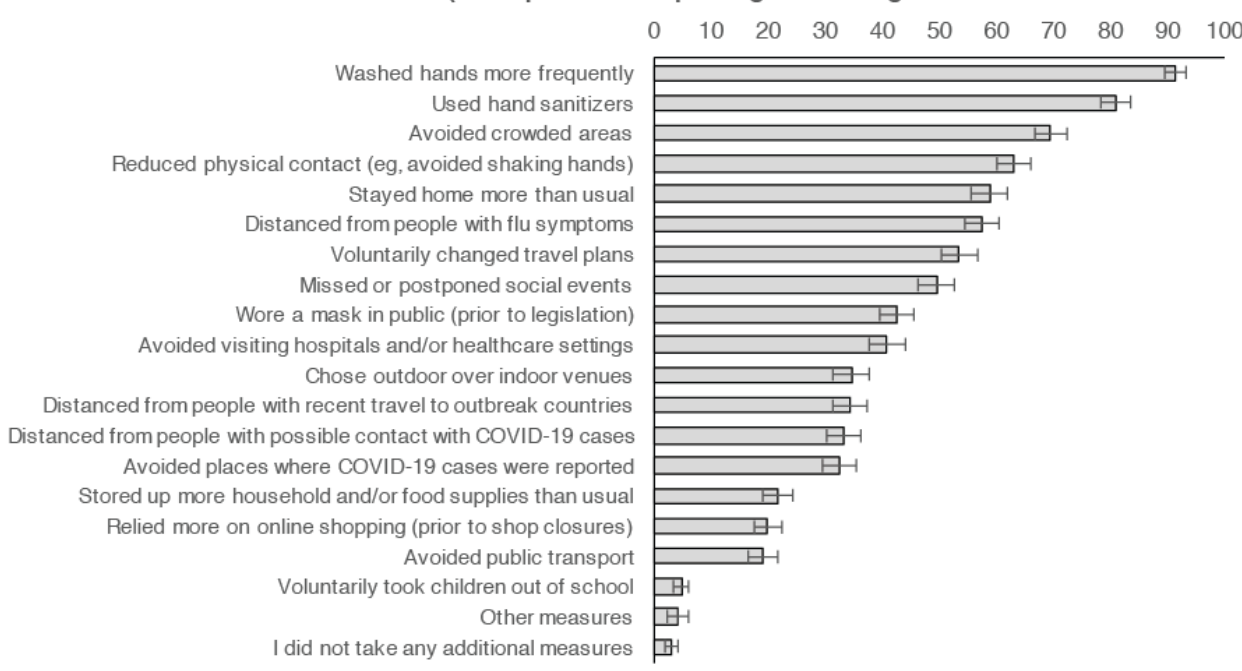

Correspondingly, the majority of participants reported normal levels of depression, anxiety, and stress symptoms on the DASS-21 scale (median scores for the depression, anxiety, and stress subscales were 5.57, 2.0, and 4.0, respectively). Nonetheless, about 1 in 10 participants $(7.9 \%)$ had severe or extremely severe symptoms on at least one subscale (Figure 2).

Figure 2. Box plots of participants' scores on the Depression, Anxiety, and Stress Scale (DASS-21). The width of the box indicates the interquartile range, while the midline depicts the median. Participants' symptoms were classified as normal, mild, moderate (Mod), severe (Sev), or extremely severe (Ext Sev). Across the three subscales, nearly 1 in 10 participants (7.9\%) reported severe or extremely severe symptoms on at least one subscale.

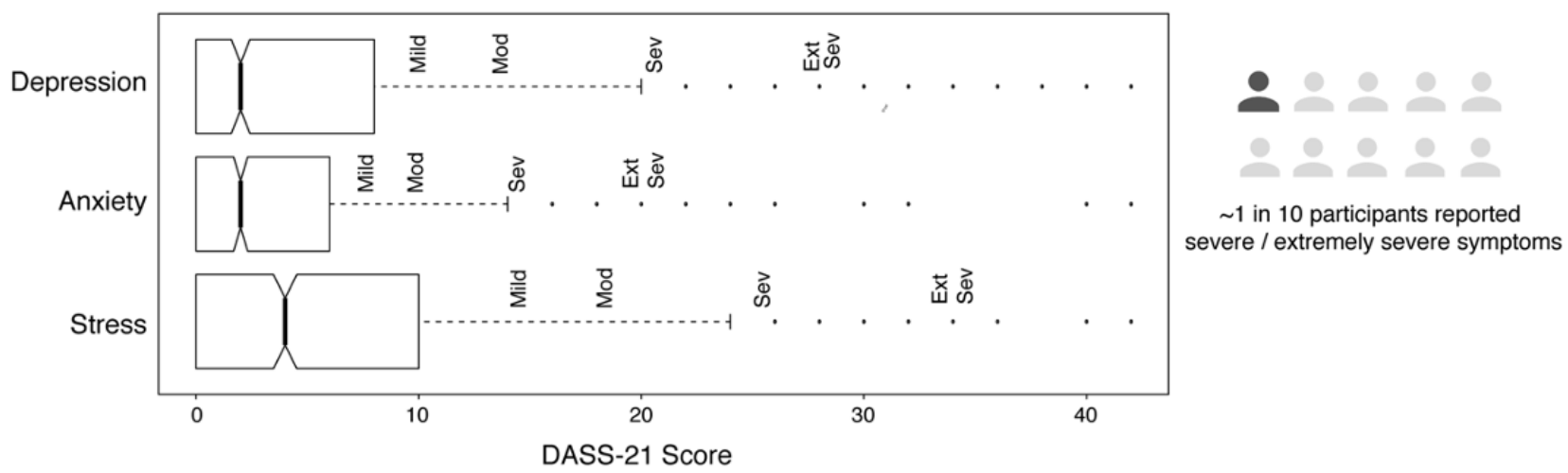




\section{Characterizing the Sample: Use of the Official WhatsApp Channel for COVID-19 News}

As shown in Figure 3, nearly 1 in 2 participants $(43.9 \%$, 95\% CI $40.8 \%-47 \%$ ) received updates from the government's
WhatsApp channel. Participants reported trusting the messages received (mean rating of 3.52 of $4,95 \%$ CI 3.48-3.56) and being likely to forward messages from this source (mean rating of 2.84 of $4,95 \%$ CI $2.78-2.90$ ).

Figure 3. Sources of COVID-19 news. Participants reported where they received COVID-19 news from (top: left panel), the extent to which they trusted each source (top: right panel), and the likelihood of them forwarding messages from each source (bottom panel). Vertical lines represent the $95 \%$ confidence intervals.
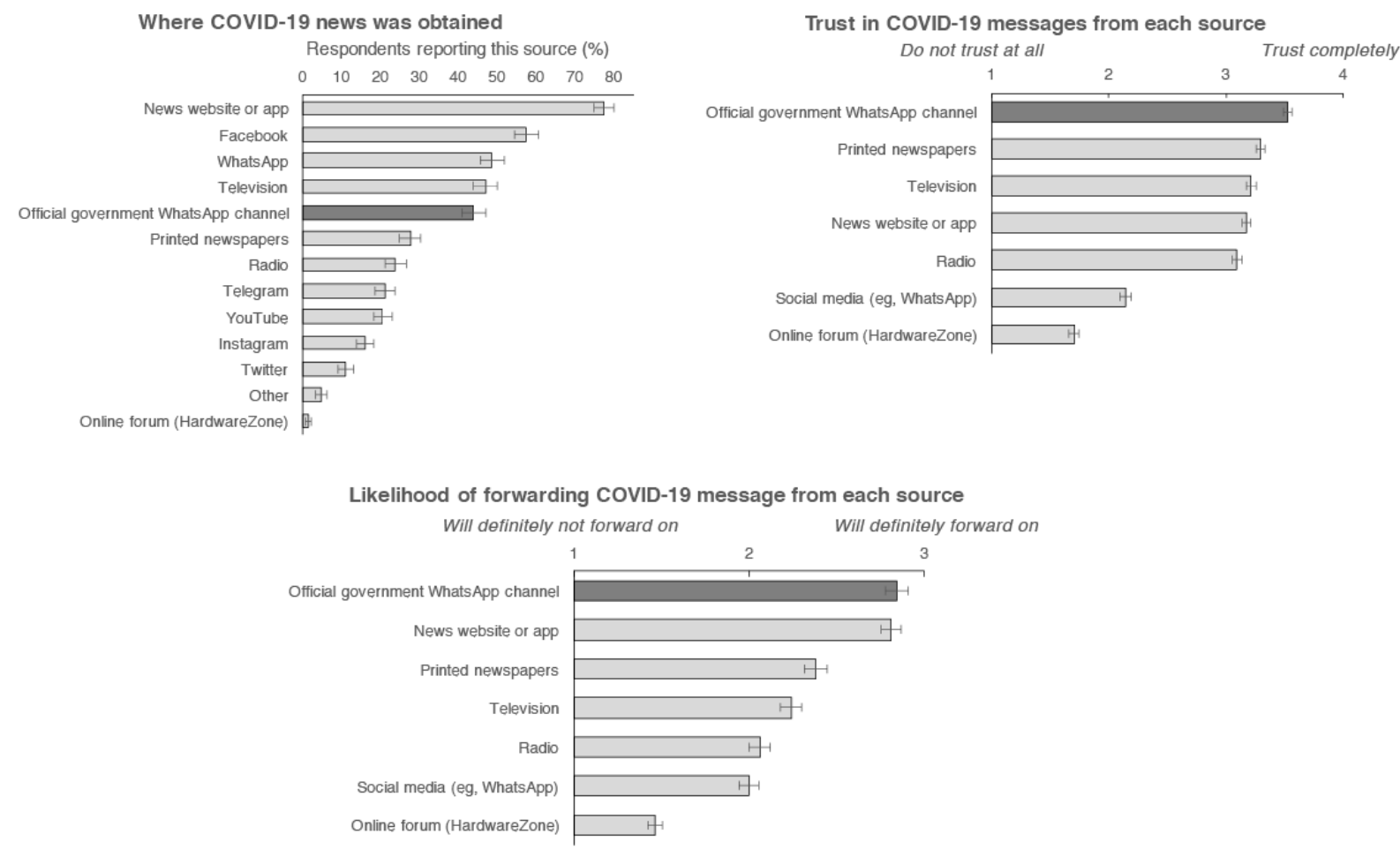

For exploratory analyses, we conducted Student $t$ tests to examine whether users of the government's WhatsApp channel differed from nonusers. On the whole, both users and nonusers cut across diverse demographic groups and were largely matched in characteristics (Table 2). However, usage increased as the outbreak progressed $(t[974]=-3.38, P=.01 ; 95 \%$ CI of the difference: 0.17-0.65 weeks). As a group, users also had a higher educational level $(t[967]=-2.27, P=.02 ; 95 \% \mathrm{CI} 0.03-0.37)$, and were more likely to be female than nonusers $\left({ }^{2}(1, \mathrm{~N}=973)=5.03\right.$, $P=.03 ; 95 \% \mathrm{CI}$ of the difference in percentage of females: $0.92 \%-12.9 \%)$. 
Table 2. Participant characteristics as a function of whether they used the official government WhatsApp channel.

\begin{tabular}{|c|c|c|c|}
\hline Characteristics & Users $(n=428)$ & Nonusers $(\mathrm{n}=548)$ & Statistic $^{\mathrm{a}}$ ( $P$ value $)$ \\
\hline Survey completion week, mean (SD) & $3.4(2.0)$ & $3.0(1.8)$ & $-3.38(.001)^{\mathrm{b}}$ \\
\hline Age (years), mean (SD) & $39.4(12.1)$ & $39.7(13.4)$ & $0.36(.72)$ \\
\hline Gender $^{c}, \mathbf{n}$ & & & $5.03(.03)^{\mathrm{b}}$ \\
\hline Female & 295 & 338 & $\mathrm{~N} / \mathrm{A}^{\mathrm{d}}$ \\
\hline Male & 133 & 207 & N/A \\
\hline Ethnicity $^{\mathbf{c}}, \mathbf{n}$ & & & $3.57(.61)$ \\
\hline Chinese & 377 & 471 & N/A \\
\hline Indian & 23 & 24 & N/A \\
\hline Malay & 11 & 14 & N/A \\
\hline Caucasian & 7 & 6 & N/A \\
\hline Filipino & 4 & 11 & N/A \\
\hline Others & 0 & 1 & N/A \\
\hline Religion $^{c}, \mathbf{n}$ & & & $7.40(.39)$ \\
\hline Christianity & 162 & 188 & N/A \\
\hline No religion & 113 & 159 & N/A \\
\hline Buddhism & 61 & 83 & N/A \\
\hline Roman Catholicism & 39 & 62 & N/A \\
\hline Taoism/Chinese traditional beliefs & 20 & 18 & N/A \\
\hline Hinduism & 16 & 12 & N/A \\
\hline Islam & 13 & 20 & N/A \\
\hline Others & 4 & 2 & N/A \\
\hline Marital status $^{\mathbf{c}}, \mathbf{n}$ & & & $9.31(.16)$ \\
\hline Married & 258 & 291 & N/A \\
\hline Single & 120 & 169 & N/A \\
\hline Dating & 40 & 65 & N/A \\
\hline Widowed, separated, or divorced & 10 & 18 & N/A \\
\hline Other & 0 & 1 & N/A \\
\hline Educational level, mean (SD) & $5.7(1.3)$ & $5.5(1.4)$ & $-2.28(.02)^{b}$ \\
\hline House type, mean (SD) & $4.1(1.1)$ & $4.1(1.2)$ & $-0.07(.95)$ \\
\hline Household size, mean (SD) & $3.7(1.2)$ & $3.7(1.2)$ & $0.02(.98)$ \\
\hline Citizenship $^{c}, \mathbf{n}$ & & & $0.11(.74)$ \\
\hline Singapore & 374 & 480 & N/A \\
\hline Other & 54 & 65 & N/A \\
\hline Country of birth ${ }^{c}, n$ & & & $0.77(.38)$ \\
\hline Singapore & 335 & 439 & N/A \\
\hline Other & 93 & 106 & N/A \\
\hline Years in Singapore, mean (SD) & $34.1(15.1)$ & $34.6(16.1)$ & 0.45 \\
\hline
\end{tabular}

${ }^{\mathrm{a}}$ Unless otherwise stated, the test statistic refers to the $t$ statistic.

${ }^{\mathrm{b}} P<.05$.

${ }^{\mathrm{c}}$ Pearson chi-square statistic reported. 
${ }^{\mathrm{d}} \mathrm{N} / \mathrm{A}$ : not applicable.

Predicting Depression, Anxiety, and Stress Symptoms During the COVID-19 Outbreak

\section{Depression Symptoms}

The following sections address the primary research question, highlighting characteristics that predict depression, anxiety, and stress symptoms on the DASS-21 scale. In terms of depression, the amount of time participants spent receiving COVID-19 updates robustly predicted well-being, with increased time spent linked to increased depression scores (Models 1-4; Table 3).
Having controlled for exposure to COVID-19 news, however, use of the government's WhatsApp channel emerged as a protective factor (Model 2). Namely, channel users reported lower depression scores than nonusers (Figure $4 ; b=-0.07$, $t[>863]=-2.04, \quad P=.04)$. This association persisted after situational and demographic factors were controlled for in Models 3 and 4, respectively. Finally, the following situational and demographic variables also predicted depression scores $(P<.05)$ : the number of local COVID-19 cases to date (Models 3 and 4), age (Model 4), and marital status (Model 4). 
Table 3. Predicting depression symptoms during the COVID-19 outbreak.

\begin{tabular}{|c|c|c|c|c|}
\hline $\begin{array}{l}\text { Dependent variable: depression symp- } \\
\text { toms (DASS-21) }\end{array}$ & Model 1 & Model 2 & Model 3 & Model 4 \\
\hline $\begin{array}{l}\text { Time spent getting COVID-19 updates } \\
\text { (hours per day) }\end{array}$ & $\begin{array}{l}0.448^{\mathrm{c}}(0.239 \text { to } \\
0.656)\end{array}$ & $0.454^{\mathrm{c}}(0.246$ to 0.662$)$ & $0.377^{\mathrm{c}}(0.169$ to 0.585$)$ & $0.389^{\mathrm{c}}(0.183$ to 0.595$)$ \\
\hline $\begin{array}{l}\text { Time spent using social media to discuss } \\
\text { or share COVID-19 information (hours } \\
\text { per day) }{ }^{b}\end{array}$ & $\begin{array}{l}0.072(-0.134 \text { to } \\
0.279)\end{array}$ & $0.073(-0.134$ to 0.280$)$ & $0.033(-0.171$ to 0.238$)$ & $0.055(-0.147$ to 0.257$)$ \\
\hline Number of COVID-19 rumors heard & $\begin{array}{l}0.009(-0.015 \text { to } \\
0.034)\end{array}$ & $0.012(-0.012$ to 0.037$)$ & $0.006(-0.019$ to 0.030$)$ & $0.010(-0.014$ to 0.034$)$ \\
\hline Number of COVID-19 rumors shared & $\begin{array}{l}0.042(-0.010 \text { to } \\
0.094)\end{array}$ & $0.040(-0.012$ to 0.092$)$ & $0.038(-0.013$ to 0.089$)$ & $0.043(-0.007$ to 0.094$)$ \\
\hline Number of COVID-19 rumors believed & $\begin{array}{l}0.037(-0.016 \text { to } \\
0.090)\end{array}$ & $0.035(-0.018$ to 0.088$)$ & $0.039(-0.013$ to 0.091$)$ & $0.033(-0.020$ to 0.085$)$ \\
\hline $\begin{array}{l}\text { Use of government's WhatsApp channel } \\
\text { (reference: nonuser) }\end{array}$ & $\mathrm{N} / \mathrm{A}^{\mathrm{d}}$ & $\begin{array}{l}-0.070^{\mathrm{e}}(-0.137 \text { to } \\
-0.003)\end{array}$ & $-0.086^{\mathrm{e}}(-0.153$ to -0.019$)$ & $-0.083^{\mathrm{e}}(-0.149$ to -0.017$)$ \\
\hline $\begin{array}{l}\text { Trust in government's WhatsApp mes- } \\
\text { sages }\end{array}$ & N/A & $\begin{array}{l}-0.032(-0.087 \text { to } \\
0.024)\end{array}$ & $-0.026(-0.061$ to 0.023$)$ & $-0.017(-0.072$ to 0.038$)$ \\
\hline $\begin{array}{l}\text { Likelihood of sharing government's } \\
\text { WhatsApp messages }\end{array}$ & N/A & $0.015(-0.020$ to 0.050$)$ & $0.014(-0.021$ to 0.049$)$ & $0.014(-0.0200 .049)$ \\
\hline Lockdown (reference: no lockdown) & N/A & N/A & $-0.077(-0.266$ to 0.111$)$ & $-0.065(-0.254$ to 0.125$)$ \\
\hline Local COVID-19 cases to date ${ }^{b}$ & N/A & N/A & $0.224^{\mathrm{c}}(0.064$ to 0.384$)$ & $0.195^{\mathrm{e}}(0.036$ to 0.355$)$ \\
\hline Age in years & N/A & N/A & N/A & $-0.004^{\mathrm{c}}(-0.007$ to -0.001$)$ \\
\hline Gender (reference: female) & N/A & N/A & N/A & $-0.006(-0.072$ to 0.059$)$ \\
\hline \multicolumn{5}{|l|}{ Ethnicity (reference: Chinese) } \\
\hline Indian & N/A & N/A & N/A & $-0.028(-0.277$ to 0.221$)$ \\
\hline Malay & N/A & N/A & N/A & $-0.316(-0.694$ to 0.062$)$ \\
\hline Filipino & N/A & N/A & N/A & $0.194(-0.126$ to 0.514$)$ \\
\hline Caucasian & N/A & N/A & N/A & $0.009(-0.255$ to 0.274$)$ \\
\hline Other & N/A & N/A & N/A & $-0.003(-0.909$ to 0.902$)$ \\
\hline \multicolumn{5}{|l|}{ Religion (reference: no religion) } \\
\hline Christianity & N/A & N/A & N/A & $-0.018(-0.097$ to 0.061$)$ \\
\hline Buddhism & N/A & N/A & N/A & $0.059(-0.041$ to 0.159$)$ \\
\hline Roman Catholicism & N/A & N/A & N/A & $<.001(-0.118$ to 0.118$)$ \\
\hline Taoism/Chinese traditional beliefs & N/A & N/A & N/A & $0.070(-0.090$ to 0.230$)$ \\
\hline Islam & N/A & N/A & N/A & $0.306(-0.068$ to 0.680$)$ \\
\hline Hinduism & N/A & N/A & N/A & $-0.124(-0.433$ to 0.185$)$ \\
\hline \multicolumn{5}{|l|}{ Marital status (reference: single) } \\
\hline Married & N/A & N/A & N/A & $-0.124^{\mathrm{c}}(-0.204$ to -0.045$)$ \\
\hline Dating & N/A & N/A & N/A & $0.051(-0.060$ to 0.162$)$ \\
\hline Widowed, separated, or divorced & N/A & N/A & N/A & $-0.114(-0.310$ to 0.082$)$ \\
\hline Educational level & N/A & N/A & N/A & $-0.007(-0.031$ to 0.018$)$ \\
\hline House type & N/A & N/A & N/A & 0.018 (-0.011 to .047$)$ \\
\hline Household size & N/A & N/A & N/A & -0.027 ( -0.056 to 0.002$)$ \\
\hline $\begin{array}{l}\text { Country of birth (reference: not Singa- } \\
\text { pore) }\end{array}$ & N/A & N/A & N/A & $-0.011(-0.097$ to 0.076$)$ \\
\hline
\end{tabular}




\begin{tabular}{lllll}
\hline $\begin{array}{l}\text { Dependent variable: depression symp- } \\
\text { toms (DASS-21) }\end{array}$ & Model 1 & Model 2 & Model 3 & Model 4 \\
\hline$R^{2}$ & .06 & .06 & .09 & .16 \\
\hline
\end{tabular}

${ }^{\mathrm{a}}$ Dependent variable: depression subscale scores from the 21 -item Depression, Anxiety, and Stress Scale (DASS-21). Data reported as beta estimates (95\% CI).

${ }^{\mathrm{b}}$ Log-transformed.

${ }^{\mathrm{c}} P<.01$.

${ }^{\mathrm{d}} \mathrm{N} / \mathrm{A}$ : not applicable.

${ }^{\mathrm{e}} P<.05$.

Figure 4. In the left panel, participants' depression scores on the Depression, Anxiety, and Stress Scale (DASS-21) have been plotted as a function of their use of the government's WhatsApp channel for COVID-19 information. In the right panel, corresponding anxiety scores have been plotted as a function of trust in the channel's messages. Vertical lines represent $95 \%$ confidence intervals.

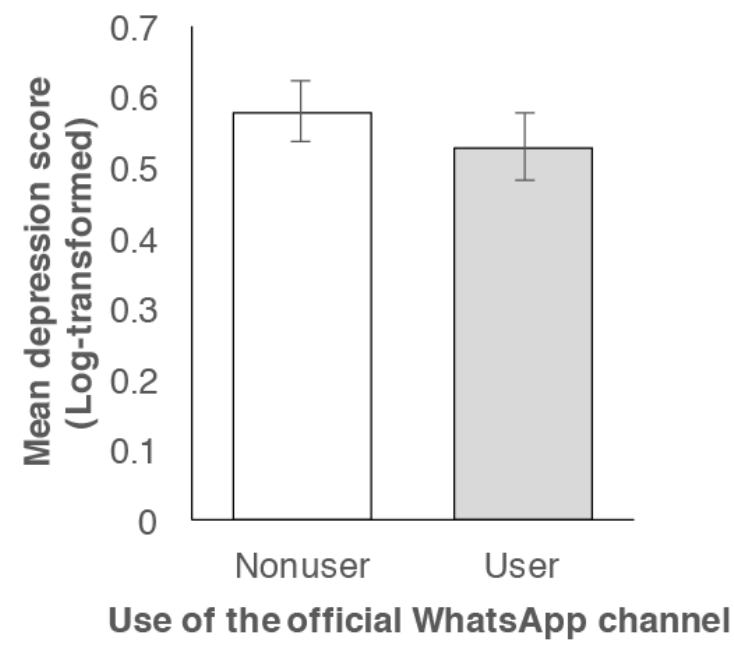

\section{Anxiety Symptoms}

As shown in Table 4, anxiety symptoms were likewise predicted by exposure to COVID-19 news in a robust manner. Across all 4 models, increased anxiety scores were associated with increased time spent obtaining COVID-19 updates and increased exposure to, sharing of, and belief of COVID-19 rumors. After controlling for these variables (Model 2), trust in the

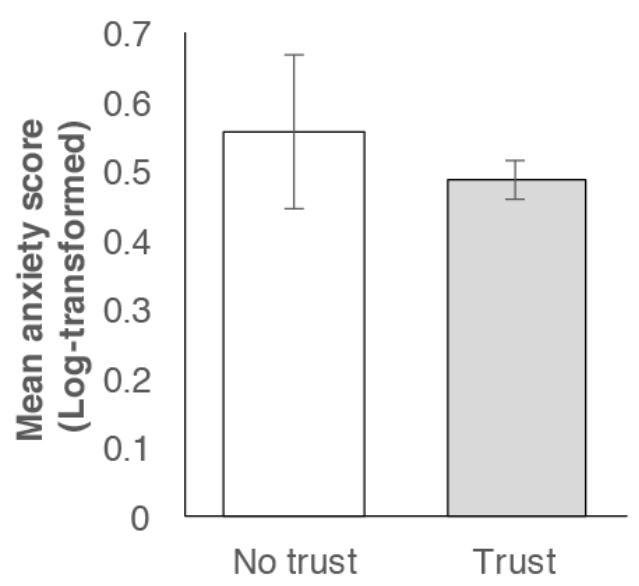

Trust in official WhatsApp messages

government's WhatsApp channel emerged as a protective factor, with increased trust predicting lower anxiety scores (Figure 4; $b=-0.05, t[863]=-2.13, P=.03)$. This relationship held when the model was adjusted for situational and demographic variables (Model 3 and 4), with the following variables emerging as additional predictors of anxiety scores $(P<.05)$ : being in a lockdown (Models 3 and 4), the number of local cases to date (Models 3 and 4), and age (Model 4). 
Table 4. Predicting anxiety symptoms during the COVID-19 outbreak.

\begin{tabular}{|c|c|c|c|c|}
\hline $\begin{array}{l}\text { Dependent variable: anxiety symptoms } \\
(\mathrm{DASS}-21)^{\mathrm{a}, \mathrm{b}}\end{array}$ & Model 1 & Model 2 & Model 3 & Model 4 \\
\hline $\begin{array}{l}\text { Time spent getting COVID-19 updates } \\
\text { (hours per day) })^{b}\end{array}$ & $\begin{array}{l}0.278^{\mathrm{c}}(0.100 \text { to } \\
0.456)\end{array}$ & $0.282^{\mathrm{c}}(0.104$ to 0.459$)$ & $0.262^{\mathrm{c}}(0.083$ to 0.442$)$ & $0.283^{\mathrm{c}}(0.104$ to 0.463$)$ \\
\hline $\begin{array}{l}\text { Time spent using social media to dis- } \\
\text { cuss or share COVID-19 information } \\
\text { (hours per day) }^{\text {b }}\end{array}$ & $\begin{array}{l}0.010(-0.166 \text { to } \\
0.187)\end{array}$ & $0.003(-0.174$ to 0.180$)$ & $-0.006(-0.183$ to 0.171$)$ & $0.002(-0.175$ to 0.178$)$ \\
\hline Number of COVID-19 rumors heard & $\begin{array}{l}0.032^{\mathrm{c}}(0.011 \text { to } \\
0.053)\end{array}$ & $0.032^{\mathrm{c}}(0.011$ to 0.053$)$ & $0.030^{\mathrm{c}}(0.009$ to 0.051$)$ & $0.033^{\mathrm{c}}(0.012$ to 0.054$)$ \\
\hline Number of COVID-19 rumors shared & $\begin{array}{l}0.083^{\mathrm{c}}(0.039 \text { to } \\
0.127)\end{array}$ & $0.080^{\mathrm{c}}(0.036$ to 0.125$)$ & $0.080^{\mathrm{c}}(0.036$ to 0.125$)$ & $0.082^{\mathrm{c}}(0.038$ to 0.126$)$ \\
\hline Number of COVID-19 rumors believed & $\begin{array}{l}0.068^{\mathrm{c}}(0.023 \text { to } \\
0.113)\end{array}$ & $0.069^{\mathrm{c}}(0.023$ to 0.114$)$ & $0.067^{\mathrm{c}}(0.022$ to 0.113$)$ & $0.062^{\mathrm{c}}(0.016$ to 0.107$)$ \\
\hline $\begin{array}{l}\text { Use of government's WhatsApp chan- } \\
\text { nel (reference: nonuser) }\end{array}$ & $N / A^{d}$ & $0.023(-0.034$ to 0.081$)$ & $0.021(-0.037$ to 0.078$)$ & $0.025(-0.032$ to 0.082$)$ \\
\hline $\begin{array}{l}\text { Trust in government's WhatsApp } \\
\text { messages }\end{array}$ & N/A & $-0.051^{\mathrm{e}}(-0.099$ to -0.004$)$ & $-0.050^{\mathrm{e}}(-0.097$ to 0.003$)$ & $-0.054^{\mathrm{e}}(-0.101$ to -0.006$)$ \\
\hline $\begin{array}{l}\text { Likelihood of sharing government's } \\
\text { WhatsApp messages }\end{array}$ & N/A & $0.017(-0.013$ to 0.047$)$ & $0.017(-0.013$ to 0.047$)$ & $0.015(-0.015$ to 0.046$)$ \\
\hline Lockdown (reference: no lockdown) & N/A & N/A & $\begin{array}{l}-0.190^{\mathrm{e}}(-0.353 \text { to } \\
-0.027)\end{array}$ & $-0.186^{\mathrm{e}}(-0.352$ to -0.021$)$ \\
\hline Local COVID-19 cases to date ${ }^{b}$ & N/A & N/A & $0.165^{\mathrm{e}}(0.027$ to 0.303$)$ & $0.151^{\mathrm{e}}(0.012$ to 0.290$)$ \\
\hline Age in years & N/A & N/A & N/A & $-0.004^{\mathrm{c}}(-0.006$ to -0.001$)$ \\
\hline Gender (reference: female) & N/A & $\mathrm{N} / \mathrm{A}$ & $\mathrm{N} / \mathrm{A}$ & $-0.036(-0.093$ to 0.022$)$ \\
\hline \multicolumn{5}{|l|}{ Ethnicity (reference: Chinese) } \\
\hline Indian & $\mathrm{N} / \mathrm{A}$ & $\mathrm{N} / \mathrm{A}$ & N/A & $0.135(-0.083$ to 0.352$)$ \\
\hline Malay & $\mathrm{N} / \mathrm{A}$ & N/A & N/A & $-0.038(-0.367$ to 0.292$)$ \\
\hline Filipino & N/A & $\mathrm{N} / \mathrm{A}$ & N/A & $0.057(-0.210$ to 0.324$)$ \\
\hline Caucasian & N/A & N/A & N/A & $-0.101(-0.332$ to 0.131$)$ \\
\hline Other & $\mathrm{N} / \mathrm{A}$ & $\mathrm{N} / \mathrm{A}$ & $\mathrm{N} / \mathrm{A}$ & $0.171(-0.619$ to 0.961$)$ \\
\hline \multicolumn{5}{|l|}{ Religion (reference: no religion) } \\
\hline Christianity & N/A & N/A & N/A & $-0.031(-0.100$ to 0.038$)$ \\
\hline Buddhism & N/A & $\mathrm{N} / \mathrm{A}$ & N/A & $0.050(-0.037$ to 0.138$)$ \\
\hline Roman Catholicism & $\mathrm{N} / \mathrm{A}$ & N/A & N/A & $0.033(-0.070$ to 0.135$)$ \\
\hline Taoism/Chinese traditional beliefs & N/A & $\mathrm{N} / \mathrm{A}$ & N/A & $0.035(-0.105$ to 0.175$)$ \\
\hline Islam & N/A & N/A & N/A & $0.122(-0.205$ to 0.448$)$ \\
\hline Hinduism & N/A & N/A & N/A & $-0.260(-0.530$ to 0.009$)$ \\
\hline \multicolumn{5}{|l|}{ Marital status (reference: single) } \\
\hline Married & $\mathrm{N} / \mathrm{A}$ & N/A & N/A & $-0.063(-0.132$ to 0.006$)$ \\
\hline Dating & N/A & N/A & N/A & $-0.009(-0.106$ to 0.088$)$ \\
\hline Widowed, separated, or divorced & $\mathrm{N} / \mathrm{A}$ & N/A & N/A & $-0.116(-0.287$ to 0.056$)$ \\
\hline Educational level & N/A & N/A & N/A & $-0.012(-0.034$ to 0.009$)$ \\
\hline House type & N/A & N/A & N/A & $0.017(-0.008$ to 0.042$)$ \\
\hline Household size & N/A & N/A & N/A & $-0.009(-0.034$ to 0.017$)$ \\
\hline $\begin{array}{l}\text { Country of birth (reference: not Singa- } \\
\text { pore) }\end{array}$ & N/A & N/A & N/A & $-0.041(-0.117$ to 0.034$)$ \\
\hline
\end{tabular}




\begin{tabular}{lllll}
\hline $\begin{array}{l}\text { Dependent variable: anxiety symptoms } \\
(\text { DASS-21) }\end{array}$ & Model 1 & Model 2 & Model 3 & Model 4 \\
\hline$R^{2}$ & .06 & .07 & .08 & .12
\end{tabular}

${ }^{\mathrm{a} D e p e n d e n t ~ v a r i a b l e: ~ a n x i e t y ~ s u b s c a l e ~ s c o r e s ~ f r o m ~ t h e ~ 21-i t e m ~ D e p r e s s i o n, ~ A n x i e t y, ~ a n d ~ S t r e s s ~ S c a l e ~(D A S S-21) . ~ D a t a ~ r e p o r t e d ~ a s ~ b e t a ~ e s t i m a t e s ~(95 \% ~}$ CI).

${ }^{\mathrm{b}}$ Log-transformed.

${ }^{\mathrm{c}} P<.01$.

${ }^{\mathrm{d}} \mathrm{N} / \mathrm{A}$ : not applicable.

${ }^{\mathrm{e}} P<.05$.

\section{Stress Symptoms}

Finally, Table 5 again highlights how the amount of time spent getting updates predicted stress symptoms (Models 1-4). However, there was no significant predictor related to use of

the official WhatsApp channel (Models 2-4). Nonetheless, the following variables emerged as significant predictors of stress: being in a lockdown (Models 3-4), the number of local cases to date (Models 3-4), age (Model 4), and gender (Model 4). 
Table 5. Predicting stress symptoms during the COVID-19 outbreak.

\begin{tabular}{|c|c|c|c|c|}
\hline $\begin{array}{l}\text { Dependent variable: stress symptoms } \\
\left(\text { DASS-21) }{ }^{\mathrm{a}, \mathrm{b}}\right.\end{array}$ & Model 1 & Model 2 & Model 3 & Model 4 \\
\hline $\begin{array}{l}\text { Time spent getting COVID-19 up- } \\
\text { dates (hours per day) }\end{array}$ & $0.405^{\mathrm{c}}(0.200$ to 0.611$)$ & $0.411^{\mathrm{c}}(0.206$ to 0.617$)$ & $0.353^{\mathrm{c}}(0.147$ to 0.559$)$ & $0.385^{\mathrm{c}}(0.180$ to 0.590$)$ \\
\hline $\begin{array}{l}\text { Time spent using social media to dis- } \\
\text { cuss or share COVID-19 information } \\
\text { (hours per day) }^{b}\end{array}$ & $\begin{array}{l}-0.058(-0.262 \text { to } \\
0.145)\end{array}$ & $-0.061(-0.266$ to 0.143$)$ & $-0.091(-0.294$ to 0.113$)$ & $-0.057(-0.258$ to 0.144$)$ \\
\hline Number of COVID-19 rumors heard & $0.020(-0.004$ to 0.044$)$ & $0.020(-0.004$ to 0.044$)$ & $0.015(-0.009$ to 0.039$)$ & $0.019(-0.005$ to 0.043$)$ \\
\hline Number of COVID-19 rumors shared & $0.043(-0.008$ to 0.094$)$ & 0.041 ( -0.010 to 0.092$)$ & $0.040(-0.010$ to 0.091$)$ & $0.051^{\mathrm{d}}(0.001$ to 0.101$)$ \\
\hline $\begin{array}{l}\text { Number of COVID-19 rumors be- } \\
\text { lieved }\end{array}$ & $0.031(-0.021$ to 0.084$)$ & $0.032(-0.020$ to 0.085$)$ & $0.033(0.019$ to 0.085$)$ & $0.026(-0.026$ to 0.078$)$ \\
\hline $\begin{array}{l}\text { Trust in government's WhatsApp } \\
\text { messages }\end{array}$ & N/A & $-0.048(-0.103$ to 0.007$)$ & $-0.044(-0.098$ to 0.011$)$ & $-0.048(-0.102$ to 0.007$)$ \\
\hline $\begin{array}{l}\text { Likelihood of sharing government's } \\
\text { WhatsApp messages }\end{array}$ & $\mathrm{N} / \mathrm{A}$ & $0.007(-0.028$ to 0.041$)$ & $0.006(-0.029$ to 0.041$)$ & $0.004(-0.031$ to 0.038$)$ \\
\hline Lockdown (reference: no lockdown) & N/A & N/A & $\begin{array}{l}-0.190^{\mathrm{d}}(-0.378 \text { to } \\
-0.003)\end{array}$ & $-0.204^{\mathrm{d}}(-0.393$ to -0.016$)$ \\
\hline Local COVID-19 cases to date ${ }^{b}$ & N/A & N/A & $0.254^{\mathrm{c}}(0.095$ to 0.413$)$ & $0.249^{c}(0.090$ to 0.407$)$ \\
\hline Age in years & N/A & N/A & N/A & $-0.005^{\mathrm{c}}(-0.008$ to -0.002$)$ \\
\hline Gender (reference: female) & N/A & N/A & N/A & $-0.084^{\mathrm{d}}(-0.150$ to -0.019$)$ \\
\hline Malay & N/A & N/A & N/A & $-0.290(-0.666$ to 0.086$)$ \\
\hline Filipino & N/A & N/A & N/A & $-0.017(-0.335$ to 0.301$)$ \\
\hline Caucasian & N/A & $\mathrm{N} / \mathrm{A}$ & N/A & $-0.036(-0.299$ to 0.227$)$ \\
\hline Other & N/A & N/A & N/A & $0.144(-0.756$ to 1.045$)$ \\
\hline \multicolumn{5}{|l|}{ Religion (reference: no religion) } \\
\hline Christianity & $\mathrm{N} / \mathrm{A}$ & $\mathrm{N} / \mathrm{A}$ & N/A & $-0.038(-0.117$ to 0.040$)$ \\
\hline Buddhism & N/A & N/A & N/A & $0.042(-0.057$ to 0.142$)$ \\
\hline Roman Catholicism & $\mathrm{N} / \mathrm{A}$ & $\mathrm{N} / \mathrm{A}$ & N/A & $0.050(-0.067$ to -0.167$)$ \\
\hline $\begin{array}{l}\text { Taoism/Chinese traditional be- } \\
\text { liefs }\end{array}$ & N/A & N/A & N/A & $0.069(-0.090$ to 0.229$)$ \\
\hline Islam & N/A & N/A & N/A & $0.311(-0.061$ to 0.683$)$ \\
\hline Hinduism & N/A & N/A & N/A & $-0.155(-0.462$ to 0.152$)$ \\
\hline \multicolumn{5}{|l|}{ Marital status (reference: single) } \\
\hline Married & $\mathrm{N} / \mathrm{A}$ & $\mathrm{N} / \mathrm{A}$ & $\mathrm{N} / \mathrm{A}$ & $-0.044(-0.123$ to 0.035$)$ \\
\hline Dating & N/A & N/A & N/A & $0.084(-0.027$ to 0.195$)$ \\
\hline Widowed, separated, or divorced & N/A & $\mathrm{N} / \mathrm{A}$ & $\mathrm{N} / \mathrm{A}$ & $-0.179(-0.374$ to 0.016$)$ \\
\hline Educational level & $\mathrm{N} / \mathrm{A}$ & $\mathrm{N} / \mathrm{A}$ & N/A & $0.009(-0.015$ to 0.033$)$ \\
\hline House type & N/A & N/A & N/A & $0.019(-0.010$ to 0.047$)$ \\
\hline Household size & N/A & N/A & N/A & $-0.010(-0.039$ to 0.019$)$ \\
\hline
\end{tabular}




\begin{tabular}{lllll}
\hline $\begin{array}{l}\text { Dependent variable: stress symptoms } \\
(\text { DASS-21) }\end{array}$ & Model 1 & Model 2 & Model 3 & Model 4 \\
\hline$R^{2}$ & .04 & .04 & .06 & .12 \\
\hline
\end{tabular}

${ }^{\mathrm{a}}$ Dependent variable: stress subscale scores from the 21-item Depression, Anxiety, and Stress Scale (DASS-21). Data reported as beta estimates (95\% CI).

${ }^{\mathrm{b}}$ Log-transformed

${ }^{\mathrm{c}} P<.01$.

$\mathrm{d}_{P<.05 \text {. }}$

${ }^{\mathrm{e}} \mathrm{N} / \mathrm{A}$ : not applicable.

\section{Discussion}

In the COVID-19 pandemic, digital technology offers novel solutions to disseminate public health messages [15]. Prior to this study, however, there were few studies evaluating these solutions. Accordingly, we systematically examined the governmental use of WhatsApp to provide COVID-19 updates.

As the first aim of our study, we sought to replicate previous findings that had linked psychological distress to COVID-19 news exposure [11]. This pattern also emerged in our data set, such that participants who spent more time getting updates were more likely to display depression, anxiety, and stress symptoms. Similar findings have also been reported in other crises (eg, when Hong Kong experienced social unrest, the amount of time an individual spent dwelling on sociopolitical news predicted symptoms of depression and posttraumatic stress disorder [30]). These findings raise a paradox: although transparency promotes resilience [2] and information seeking is encouraged (eg, [31]), a longer amount of time spent doing so is a marker for poor psychological health.

Construing exposure to COVID-19 news as a modifiable risk factor, one possible way to mitigate risk may be through spreading official advisories via social media. In particular, messenger-based platforms allow a government's advisories to reach a large number of people near-instantly, minimizing the need for individuals to search for updates themselves or to sift through misinformation. In support of this case, we observed that having controlled for news exposure, subscription to a government's WhatsApp channel was associated with fewer depression symptoms. Similarly, increased trust in official WhatsApp messages was associated with decreased anxiety. Both these associations were robust and were observed even after situational and demographic characteristics had been adjusted for.

Although preliminary, it is promising that using an official WhatsApp channel may boost psychological resilience. Further research is needed to identify what mechanisms may underlie these findings. One possibility is that WhatsApp allows fast message transmission, curbing the spread of rumors that may provoke anxiety. Alternatively, the use of an official WhatsApp channel may boost trust in the institution, a factor that has been linked with reduced anxiety in times of crisis (eg, the nuclear disaster in Fukushima) [32,33]. Although these accounts are consistent with anxiety being characterized by worry and the threat of danger (such that increased trust in official messages can allay fears) [34], it is less clear why use of the WhatsApp channel was linked to attenuated depression symptoms.

Mechanisms notwithstanding, another important observation was that the official WhatsApp service was adopted by persons of diverse demographic backgrounds. This stands in contrast to traditional findings of certain groups being more technologically savvy (eg, young adults) [35], and likely reflects the broad appeal of WhatsApp (which reports over 2 billion users across 180 countries [36]). Aside from its take-up, participants also reported being willing to forward COVID-19 messages from this source. Consequently, the features of an official WhatsApp service may render it suitable for addressing false information during the current "infodemic."

In presenting these findings, we note several limitations of our study. First, we used the approach of large-scale epidemiological surveys, examining the real-life usage of an official WhatsApp channel. Although this design is appropriate for new areas of research, the cross-sectional design precludes strong conclusions about causality. Accordingly, future studies should consider randomized controlled trials (eg, by offering subscription to a random sample of a population when a new WhatsApp service is rolled out). Second, we chose to study WhatsApp because of its large worldwide subscription base and because it is the most widely used messenger platform in official deployment (eg, by the WHO and individual governments). In making this choice, however, we were unable to draw conclusions about other messenger-based platforms (eg, Telegram). Finally, we caution the reader about several features of our study that can limit generalizability. Although we sampled from a wide array of demographic groups, our final set of respondents was not representative of the general population. Correspondingly, further research is needed to examine whether our findings can generalize to populations we have undersampled (eg, participants $>65$ years of age who may be less likely to respond to online recruitment methods). In addition, we note that the context for COVID-19 research is changing rapidly across countries as well as time (eg, number of COVID-19 cases, progress of vaccine research, government-level implementation of infection control measures). Notably, participants in our sample had high trust in official WhatsApp messages and displayed confidence that the government could manage the spread of COVID-19. Moving forward, future research will need to examine the extent to which these elements are crucial to WhatsApp's effectiveness. To this end, we have provided detailed documentation on the context of our research, allowing the reader to make informed judgments regarding generalizability. 
In conclusion, the COVID-19 pandemic has developed against a backdrop of innovative solutions for widespread communication. In unprecedented times, these solutions have the potential to boost psychological resilience; as we reported in this study, one such solution is the use of WhatsApp by a government to disseminate local updates. Given the promising nature of our findings, we encourage governments and transgovernmental bodies to explore these digital technologies. We further encourage researchers to empirically evaluate the impact of these solutions.

\section{Acknowledgments}

This research was funded by a grant awarded to JCJL from the JY Pillay Global Asia Programme (grant number: IG20-SG002). The authors gratefully acknowledge Kylie Heng, Joseph Chin, and Russell Wee for their assistance in preparing and launching the survey. We are also grateful to Synergy Lab members for their feedback on early drafts of the survey.

\section{Conflicts of Interest}

None declared.

\section{Multimedia Appendix 1}

Means, standard deviation, and Spearman rho for predictors related to official WhatsApp use. [DOCX File, 45 KB-Multimedia Appendix 1]

\section{References}

1. WHO Director-General's opening remarks at the media briefing on COVID-19 - 11 March 2020. World Health Organization. 2020. URL: https://www.who.int/dg/speeches/detail/

who-director-general-s-opening-remarks-at-the-media-briefing-on-covid-19---11-march-2020 [accessed 2020-09-03]

2. Wang C, Pan R, Wan X, Tan Y, Xu L, Ho CS, et al. Immediate Psychological Responses and Associated Factors during the Initial Stage of the 2019 Coronavirus Disease (COVID-19) Epidemic among the General Population in China. Int J Environ Res Public Health 2020 Mar 06;17(5):1729 [FREE Full text] [doi: 10.3390/ijerph17051729] [Medline: 32155789]

3. Coronavirus disease (COVID-19): Situation report - 106. World Health Organization. 2020. URL: https://www.who.int/ docs/default-source/coronaviruse/situation-reports/20200505covid-19-sitrep-106.pdf?sfvrsn=47090f63 2 [accessed 2020-09-03]

4. Kaplan J, Frias L, McFall-Johnsen M. A third of the global population is on coronavirus lockdown - here's our constantly updated list of countries locking down and opening up. Business Insider. 2020. URL: https://www.businessinsider.com/ countries-on-lockdown-coronavirus-italy-2020-3?r=DE\&IR=T [accessed 2020-09-03]

5. Torales J, O'Higgins M, Castaldelli-Maia JM, Ventriglio A. The outbreak of COVID-19 coronavirus and its impact on global mental health. Int J Soc Psychiatry 2020 Jun;66(4):317-320. [doi: 10.1177/0020764020915212] [Medline: 32233719]

6. Bo H, Li W, Yang Y, Wang Y, Zhang Q, Cheung T, et al. Posttraumatic stress symptoms and attitude toward crisis mental health services among clinically stable patients with COVID-19 in China. Psychol Med 2020 Mar 27:1-2 [FREE Full text] [doi: 10.1017/S0033291720000999] [Medline: 32216863]

7. Ahmed MZ, Ahmed O, Aibao Z, Hanbin S, Siyu L, Ahmad A. Epidemic of COVID-19 in China and associated Psychological Problems. Asian J Psychiatr 2020 Apr 14;51:102092 [FREE Full text] [doi: 10.1016/j.ajp.2020.102092] [Medline: 32315963]

8. Tian F, Li H, Tian S, Yang J, Shao J, Tian C. Psychological symptoms of ordinary Chinese citizens based on SCL-90 during the level I emergency response to COVID-19. Psychiatry Res 2020 Jun;288:112992 [FREE Full text] [doi:

10.1016/j.psychres.2020.112992] [Medline: 32302816]

9. Lee SA, Jobe MC, Mathis AA. Mental health characteristics associated with dysfunctional coronavirus anxiety. Psychol Med 2020 Apr 16:1-2 [FREE Full text] [doi: 10.1017/S003329172000121X] [Medline: 32297852]

10. \#HealthyAtHome. World Health Organization. 2020. URL: https://www.who.int/news-room/campaigns/ connecting-the-world-to-combat-coronavirus/healthyathome?gclid= [accessed 2020-09-03]

11. Huang Y, Zhao N. Generalized anxiety disorder, depressive symptoms and sleep quality during COVID-19 outbreak in China: a web-based cross-sectional survey. Psychiatry Res 2020 Jun;288:112954 [FREE Full text] [doi: 10.1016/j.psychres.2020.112954] [Medline: $\underline{32325383}$ ]

12. Gao J, Zheng P, Jia Y, Chen H, Mao Y, Chen S, et al. Mental health problems and social media exposure during COVID-19 outbreak. PLoS One 2020;15(4):e0231924 [FREE Full text] [doi: 10.1371/journal.pone.0231924] [Medline: $\underline{32298385]}$

13. Ni MY, Yang L, Leung CMC, Li N, Yao XI, Wang Y, et al. Mental Health, Risk Factors, and Social Media Use During the COVID-19 Epidemic and Cordon Sanitaire Among the Community and Health Professionals in Wuhan, China: Cross-Sectional Survey. JMIR Ment Health 2020 May 12;7(5):e19009 [FREE Full text] [doi: 10.2196/19009] [Medline: 32365044]

14. Novel coronavirus (2019-nCoV) Situation Report - 13. World Health Organization. 2020 Feb 02. URL: https://www.who.int/ docs/default-source/coronaviruse/situation-reports/20200202-sitrep-13-ncov-v3.pdf [accessed 2020-09-03] 
15. Ting DSW, Carin L, Dzau V, Wong TY. Digital technology and COVID-19. Nat Med 2020 Apr;26(4):459-461 [FREE Full text] [doi: 10.1038/s41591-020-0824-5] [Medline: 32284618]

16. Limaye RJ, Sauer M, Ali J, Bernstein J, Wahl B, Barnhill A, et al. Building trust while influencing online COVID-19 content in the social media world. Lancet Digit Health 2020 Jun;2(6):e277-e278 [FREE Full text] [doi: 10.1016/S2589-7500(20)30084-4] [Medline: 32322814]

17. Australian government WhatsApp channel for COVID-19. Australian Government Department of Health. 2020. URL: https://www.health.gov.au/resources/apps-and-tools/australian-government-whatsapp-channel-for-covid-19 [accessed 2020-09-03]

18. WHO Health Alert brings COVID-19 facts to billions via WhatsApp. World Health Organization. 2020. URL: https://www. who.int/news-room/feature-stories/detail/who-health-alert-brings-covid-19-facts-to-billions-via-whatsapp [accessed 2020-09-03]

19. Iqbal M. WhatsApp revenue and usage statistics. Business of Apps. 2020. URL: https://www.businessofapps.com/data/ whatsapp-statistics/ [accessed 2020-09-03]

20. Toppenberg-Pejcic D, Noyes J, Allen T, Alexander N, Vanderford M, Gamhewage G. Emergency Risk Communication: Lessons Learned from a Rapid Review of Recent Gray Literature on Ebola, Zika, and Yellow Fever. Health Commun 2019 Apr;34(4):437-455. [doi: 10.1080/10410236.2017.1405488] [Medline: 29558199]

21. Yip WY. Budget debate: Digital medical certificates to be rolled out to private healthcare sector. The Straits Times. 2020. URL: https://www.straitstimes.com/singapore/ budget-debate-digital-medical-certificates-to-be-rolled-out-to-private-healthcare-sector [accessed 2020-09-03]

22. OSF | COVID-19 in Singapore: A nation-wide survey. 2020 Jun 24. URL: https://osf.io/pv3bj [accessed 2020-09-07]

23. Coronavirus disease (COVID-19) advice for the public: Mythbusters. World Health Organization. 2020. URL: https://www. who.int/emergencies/diseases/novel-coronavirus-2019/advice-for-public/myth-busters [accessed 2020-09-03]

24. Chua AY, Banerjee S. Intentions to trust and share online health rumors: An experiment with medical professionals. Computers in Human Behavior 2018 Oct;87:1-9. [doi: 10.1016/j.chb.2018.05.021]

25. Oei TPS, Sawang S, Goh YW, Mukhtar F. Using the Depression Anxiety Stress Scale 21 (DASS-21) across cultures. Int J Psychol 2013;48(6):1018-1029. [doi: 10.1080/00207594.2012.755535] [Medline: 23425257]

26. Chew NWS, Lee GKH, Tan BYQ, Jing M, Goh Y, Ngiam NJH, et al. A multinational, multicentre study on the psychological outcomes and associated physical symptoms amongst healthcare workers during COVID-19 outbreak. Brain Behav Immun 2020 Aug;88:559-565 [FREE Full text] [doi: 10.1016/j.bbi.2020.04.049] [Medline: 32330593]

27. Mesch GS, Schwirian KP. Vaccination hesitancy: fear, trust, and exposure expectancy of an Ebola outbreak. Heliyon 2019 Jul;5(7):e02016 [FREE Full text] [doi: 10.1016/j.heliyon.2019.e02016] [Medline: 31367685]

28. Bali S, Stewart KA, Pate MA. Long shadow of fear in an epidemic: fearonomic effects of Ebola on the private sector in Nigeria. BMJ Glob Health 2016;1(3):e000111 [FREE Full text] [doi: 10.1136/bmjgh-2016-000111] [Medline: 28588965]

29. Vinck P, Pham PN, Bindu KK, Bedford J, Nilles EJ. Institutional trust and misinformation in the response to the 2018-19 Ebola outbreak in North Kivu, DR Congo: a population-based survey. Lancet Infect Dis 2019 May;19(5):529-536. [doi: 10.1016/S1473-3099(19)30063-5] [Medline: 30928435]

30. Ni MY, Yao XI, Leung KSM, Yau C, Leung CMC, Lun P, et al. Depression and post-traumatic stress during major social unrest in Hong Kong: a 10-year prospective cohort study. Lancet 2020 Jan 25;395(10220):273-284. [doi: 10.1016/S0140-6736(19)33160-5] [Medline: 31928765]

31. Coronavirus (COVID-19). Centers for Disease Control and Prevention. 2020. URL: https://www.cdc.gov/coronavirus/ 2019-ncov/index.html [accessed 2020-09-03]

32. Cheung C, Tse JW. Institutional trust as a determinant of anxiety during the SARS crisis in Hong Kong. Soc Work Public Health 2008;23(5):41-54. [doi: 10.1080/19371910802053224] [Medline: 19301537]

33. Tateno S, Yokoyama HM. Public anxiety, trust, and the role of mediators in communicating risk of exposure to low dose radiation after the Fukushima Daiichi Nuclear Plant explosion. JCOM 2013;12(02):A03. [doi: 10.22323/2.12020203]

34. Eysenck MW, Fajkowska M. Anxiety and depression: toward overlapping and distinctive features. Cogn Emot 2018 Nov;32(7):1391-1400. [doi: 10.1080/02699931.2017.1330255] [Medline: 28608767]

35. Vogels EA. Millennials stand out for their technology use, but older generations also embrace digital life. Pew Research Center. 2019 Sep 09. URL: https://www.pewresearch.org/fact-tank/2019/09/09/us-generations-technology-use/ [accessed 2020-09-03]

36. Number of monthly active WhatsApp users worldwide from April 2013 to March 2020. Statista. 2020 Apr 30. URL: https:/ /www.statista.com/statistics/260819/number-of-monthly-active-whatsapp-users/ [accessed 2020-09-03]

\section{Abbreviations \\ WHO: World Health Organization}


Edited by G Eysenbach; submitted 04.07.20; peer-reviewed by M Subramaniam, Q Liao, MY Ni; comments to author 05.08.20; revised version received 13.08.20; accepted 01.09.20; published 25.09.20

Please cite as:

Liu JCJ, Tong EMW

The Relation Between Official WhatsApp-Distributed COVID-19 News Exposure and Psychological Symptoms: Cross-Sectional Survey Study

J Med Internet Res 2020;22(9):e22142

URL: http://www.jmir.org/2020/9/e22142/

doi: $\underline{10.2196 / 22142}$

PMID: $\underline{32877349}$

(CJean C J Liu, Eddie M W Tong. Originally published in the Journal of Medical Internet Research (http://www.jmir.org), 25.09.2020. This is an open-access article distributed under the terms of the Creative Commons Attribution License (https://creativecommons.org/licenses/by/4.0/), which permits unrestricted use, distribution, and reproduction in any medium, provided the original work, first published in the Journal of Medical Internet Research, is properly cited. The complete bibliographic information, a link to the original publication on http://www.jmir.org/, as well as this copyright and license information must be included. 